\title{
The Effects of Deregulation on the Performance of Financial Institutions: The Case of Spanish Savings Banks*
}

\author{
Subal C. Kumbhakar \\ Department of Economics \\ University of Texas at Austin \\ Austin, Texas 78712-1173 \\ E-mail: kkar@eco.utexas.edu \\ Ana Lozano-Vivas \\ Dpto de Teoría e Historia Económica \\ Facultad CC.EE., Universidad de Málaga \\ Plza. El Ejido s/n. 29013 Málaga, Spain \\ E-mail: avivas@uma.es \\ C. A. Knox Lovell \\ Department of Economics \\ University of New South Wales \\ Sydney, NSW, Australia \\ E-mail: k.lovell@unsw.edu.au \\ and \\ Iftekhar Hasan \\ Department of Finance \\ New York University \\ 44 West Fourth Street \\ New York, NY 10012 \\ E-mail: ihasan@stern.nyu.edu
}

\begin{abstract}
This paper examines the impact of regulatory reform on the performance of Spanish savings banks. To this end it uses panel data for the period 1986-1995 and a flexible variable profit function that incorporates timevarying technical efficiency. The focus is whether increased competition brought on by deregulation affected performance of banks over time. Bank performance, measured by the percentage change in profitability, ceteris paribus, is decomposed into technical change and change in technical efficiency both of which are defined in terms of the profit function. We also examine output technical efficiency, which is defined in terms of the production possibility frontier. Several alternative models with different specifications of technical efficiency are used to check robustness of the results. Empirical results show declining levels of output technical efficiency along with a significantly high rate of technical progress. In spite of declining technical efficiency during this period, we find evidence of an increasing trend in productivity growth.
\end{abstract}

JEL Classification Number: L94

\footnotetext{
* We thank Allen Berger on an earlier version of the paper. However, we alone are responsible any any remaining errors. LozanoVivas acknowleges the financial support from the DGICYT, PS95-0176.
} 


\section{INTRODUCTION}

In recent decades, the banking sectors of many industrialized countries have been subjected to various forms of deregulation. Apparently, the policy makers believe that improving the efficiency and performance of financial systems is better implemented through deregulatory policies aiming at increasing bank competition on price, product, services, and territorial rivalry (Smith, 1997). However the empirical evidence on the impact of such initiatives has been mixed.

Berger and Humphrey (1997) state that the consequences of the deregulation may essentially depend on industry conditions prior to deregulation process as well as on the type of deregulation measures implemented. The deregulation on the asset side of the balance sheet that has focused on the liberalization of the volume and the interest rates of bank lending have resulted in improvement of both efficiency and productivity of Norwegian banks (Berg, Forsund, and Jansen, 1992). Similarly, the Turkish banks had the same experience (Zaim, 1995). However, the impact of liberalization on Indian banks has resulted in varied productivity efficiency depending on the different type of ownership (Bhattacharyya, Lovell and Sahay, 1997).

On the contrary, the deregulation measures pertaining to the deposit rates competition have not changed efficiency levels in the U.S. banking industry (Bauer, Berger, and Humphrey 1993; Elsiani and Mehdian, 1995). In fact, U.S. banks have experienced decline in productivity growth (Humphrey, 1993; Humphrey and Pulley, 1997). In Korea however, it was the privatization of the banking industry rather than its interest rate deregulation on deposits that has resulted in increased output and productivity (Gilbert and Wilson, 1998). In Japan, the collapse of its bubble economy led to a rather stable technical efficiency level over time, however the productivity growth and efficiency change differed across banks and organization forms (Fukuyama, 1995). With regards to geographical deregulation and consolidation in the U.S., Hughes, Lang, Mester, and Moon (1996) have reported efficiency to increase with additional operation thus confirming the benefits from geographical expansion. ${ }^{1}$ Recently, Wheelock and Wilson (1999) reported declining efficiency and productivity of U.S. banks, especially small banks, during the 1984 and 1993 period. However, the paper did not explicitly focus on the impact of deregulatory changes during the sample period.

In Spain, a number of studies have focused on the performance of banks during the deregulatory period. ${ }^{2}$ Although a variety of specific findings emerged from these studies, two features stand out. First, the evidence indicates a limited change in productivity and an increase in inefficiency in both commercial and savings bank sectors. Second, the decline of performance was relatively less for the savings banks that

\footnotetext{
${ }^{1}$ For an extensive review of literature on the bank performance and efficiency due to consolidation and related issues see Berger, Demsetz, and Strahan (1999).
} 
were subjected to more deregulatory measures in recent years. ${ }^{3}$ These findings might be due to the fact that banks have had a difficult time adjusting to the increased freedom and competition created by deregulation.

Despite their stated intentions to investigate the bank performance during the deregulation era in Spain, most studies tended to focus on measuring the level of efficiency and/or productivity growth over time without linking them to the deregulatory process. In fact, these papers focused more on the use of frontier technique instead of explaining the deregulatory process. Although, Grifell and Lovell (1996) attempted to undertake such explanation their study specifically concentrated on analyzing productivity change. Overall, the above studies have either estimated the efficiency and productivity growth measures from a cost-minimizing framework or have used a non-parametric technique designed to obtain results on technical inefficiency of inputs. However, the recent literature has established ${ }^{4}$ the superiority of profit efficiency over the cost efficiency measures for evaluating the overall performance of banks.

In this study, we employ a short-run profit function to investigate the effect of deregulation on the performance of Spanish savings banks. We concentrate on savings banks because many of the deregulatory initiatives were specifically designed for this sector of the industry since commercial banks had already been benefiting from similar deregulatory measures for years. Moreover, in recent years, the savings banks have shown aggressive gain in market shares relative to other banking institutions.

Unlike other studies, the present study uses a longer time horizon and a state-of-the-art econometric approach to examine the effect of the deregulation process on productivity growth, technical change, and efficiency. It considers a model that is based on the profit maximizing behavior and measures both technical inefficiency and profit loss therefrom for each bank and for every year. ${ }^{5}$ We allow technical efficiency to vary through time in order to examine whether the deregulatory measures enhanced profitability and efficiency of savings banks over time. Finally, it measures productivity growth, which is then decomposed into change in technical efficiency and technical change. Such a separation of technical inefficiency from technical change is important because it allows one to decompose productivity change into technical change (a shift in the profit frontier over time) and change in technical efficiency (a movement toward the frontier). ${ }^{6}$ Instead of using the traditional cost-minimizing framework, this is the only study - except for Berger and Mester (1999) - that investigates the productivity growth in a profit-maximizing framework. Overall, our

\footnotetext{
${ }^{2}$ For example, see Grifell and Lovell $(1996,1997)$ and Lozano-Vivas $(1997,1998)$ and the references cited in there for papers dealing with deregulatory initiatives during the mid 1980s.

${ }_{3}^{3}$ One explanation to these results could be that the savings banks sample is more homogeneous than that of the commercial banks sample.

${ }^{4}$ For example, see Berger, Hancock and Humphrey (1993), Berger and Humphrey (1997) and Berger and Mester (1999).

${ }^{5}$ Previous studies using a profit function approach focused on profit inefficiency alone because it was believed that estimation of both technical inefficiency and profit loss therefrom cannot be achieved unless the underlying production technology is quite restrictive (self-dual), see Kumbhakar (1996).
} 
evidence reveals a high level of technical inefficiency along with a very high rate of technical progress. Despite increased technical inefficiency during the sample period we see evidence of productivity growth.

The rest of the paper is organized as follows. The next section briefly describes the Spanish banking system and recent deregulatory initiatives. The model is introduced in Section 3. Section 4 describes the data. The estimation method is discussed in Section 5 and empirical results are presented in Section 6. The final section contains a summary of our findings and conclusions.

\section{SPANISH BANKS AND DEREGULATION INITIATIVES}

The Spanish banking system consists of commercial banks, savings banks and credit cooperatives. The first two sectors contain over $95 \%$ of the banking assets. Since the recent wave of deregulation, primarily during the 1985-1990 period, savings banks have been more successful in gaining market share at the expense of the private commercial banks. This new emergence of saving banks in the deposit market as well as in the loan market has diminished the traditional dominance of private commercial banks in the Spanish banking industry. ${ }^{7}$

After a series of small initiatives undertaken in the late 1960s, deregulation efforts were intensified during the mid-1980s. The primary reason for this rapid liberalization process was to keep the competitive edge of the local banking and financial markets at par with other European countries after the removal of barriers to inter-country competition in financial services within the European Economic Community. Over the years, the focus of deregulation in Spain have been to eliminate interest rate controls and investment requirements, to relax reserve requirements, to promote branch expansion and to ease entry of foreign banks in the local markets.

Equal investment requirements established for commercial and savings banks in 1985 were gradually phased out during 1989-1992. Reserve requirements were lowered in 1992 and entry restrictions for foreign financial institutions started in 1986. All interest rates and commissions were deregulated in 1987 and credit ceilings were lifted by 1990. While branching of commercial banks was freely allowed in 1985, restrictions on savings banks remained in effect until $1989 .{ }^{8}$ Overall, in the past two decades, the Spanish banking industry has gone from a strongly regulated oligopolistic system to a new environment where the banks can compete through prices or quality of services, with very little regulatory and entry restrictions on institutions and markets.

\footnotetext{
${ }^{6}$ It is not always possible to separate the two effects without making distributional assumptions on technical inefficiency (Kumbhakar (1990)).

7 For more details on changes in market structures and relative market share and strategies undertaken by the two sectors, see Canals (1997) and Hasan, Hunter, and Lozano-Vivas (1999).
} 
While commercial banks were traditionally oriented towards corporate business, savings banks primarily served retail customers. Most of these savings bank customers held low average balances and valued convenience and proximity of branch offices. After the regulatory reform process began, the commercial and savings banks followed different strategies in adapting to the new financial market. Commercial banks focused more on adjusting their deposit and loan rates to meet increased competition. In contrast, savings banks pursued a growth strategy by expanding branch and ATM network and undertaking a series of mergers.

The deregulatory measures altered the competitive structure of the banking market causing tangible changes in savings banks' income statement and balance sheet during the sample years. Table 1 depicts statistics of a number of bank- and market-specific variables that are pertinent to our analyses. For brevity, the table reports information on certain sample years and the averages before and after 1990 to provide a general view of the industry experience during the deregulatory and post deregulatory periods. ${ }^{9}$ Among the significant observations during this period was the fall in the financial margin, from $4.9 \%$ over assets in 1986 to $3.8 \%$ in 1995 . In fact, during the 1991-1993 period, the average margin was even lower at $3.5 \%$ in 1991 and $2.9 \%$ in 1993. This drop in financial margin was basically due to increasing interest cost for deposits caused by the enhanced competition in the market. Banks attempted to adjust to the new environment by extending, among others, non-depository banking activities thus increasing earning from service fees and related businesses. In fact, earnings from service fee increased from a $0.28 \%$ over assets in 1986 to $0.56 \%$ in 1995 . This evidence of changes in earning patterns reflects a structural change in the banking industry and market rivalry.

Relaxation of branching restrictions accelerated saving banks' desire to take a more prominent role in the banking market. They pursued a growth strategy by expanding branch network and undertaking a series of mergers. This has prompted a $17 \%$ increase in number of branches during the sample period and contributed to a $38 \%$ decline in the number of savings banks. There was a phenomenal increase in the number of ATMs per bank (from 40 in 1986 to 301 in 1995, i.e., a 652\% increase). During this time period, the savings banks also decided to initiate an increase in price competition that was facilitated by an earlier deregulation in interest rate. ${ }^{10}$ Overall, the net effect has been a substantial increase in the market share of the savings banks. Their market share for deposits was $45.3 \%$ in 1995 compared to a $40.1 \%$ in 1986 . The progressive liberalization of the savings banks' activities has also brought a change of their product mix, e.g., the loan to deposit ratio increased by $37 \%$. These banks successfully expanded their market share in

\footnotetext{
${ }^{8}$ For an extensive overview of the liberalization process, see Vives (1990, 1991a, 1991b); and Hasan, Hunter, and Lozano-Vivas (1999).

${ }^{9}$ The 1986-1990 indicates a time period when most of the deregulatory initiaves were undertaken whereas 1991-1995 period represent post deregulatory period. Statistics for each of the sample years are available upon request.
} 
both deposit and loan markets capturing the later at a relatively faster rate implying certain qualitative differences in their product mix.

In order to have a better insight on the impact of deregulatory changes and developments on productivity, efficiency, and technical change we go beyond these sample statistics ${ }^{11}$ and develop a variable profit function model. This profit function approach controls for variations in prices (inputs and outputs) and other quasi-fixed inputs/output attributes while examining efficiency, productivity growth, and technical change. The following section briefly describes the variable profit function with technical inefficiency.

\section{THE MODEL}

Let $y=\left(y_{1}, \ldots, y_{M}\right)$ be a vector of $M$ outputs produced by the banks using $x=\left(x_{1}, \ldots, x_{J}\right)$, a vector of $J$ variables inputs, and $z=\left(z_{1}, \ldots, z_{Q}\right)$, a vector of $Q$ quasi-fixed inputs and/or output characteristics. We write the production technology (better known as the production possibility frontier) as $F\left(y e^{u}, x, z, t\right)=0$, where $y$ is the observed output vector, $t$ is time (in years), and $u \geq 0$ is output technical inefficiency. Output technical efficiency is measured by $\left(e^{-u}\right)$. By technical (in)efficiency we mean output technical (in)efficiency throughout our analysis.

Since we assume that the objective of banks is to maximize variable profit both variable inputs and outputs are decision variables. Consequently, optimum levels of variable inputs used and outputs produced will depend on the level of technical inefficiency. The optimization problem for a bank can be formally written as

$$
\begin{aligned}
& \max _{y, x} \pi^{a}=p^{\prime} y-w^{\prime} x \Leftrightarrow \max _{y e^{u}, x} \pi^{a} e^{u}=p^{\prime} y e^{u}-w^{\prime} e^{u} x \\
& \text { s.t. } \quad F\left(y e^{u}, x, z, t\right)=0,
\end{aligned}
$$

where $p=\left(p_{1}, \ldots, p_{M}\right)^{\prime}$ is the vector of output prices and $w=\left(w_{1}, \ldots, w_{J}\right)^{\prime}$ is the variable input price vector.

The solution of the above problem gives the following form of the efficiency adjusted variable profit $\pi^{a} e^{u}$, viz.,

$$
\begin{aligned}
\pi^{a} e^{u} & =\sum_{m} p_{m} y_{m} e^{u}-\sum_{j} w_{j} e^{u} x_{j} \\
& =\sum_{m} p_{m} \psi_{m}(.)-\sum_{j} w_{j} e^{u} \phi_{j}(.)=\pi\left(w e^{u}, p, z, t\right),
\end{aligned}
$$

where $\psi_{\mathrm{m}}$ and $\phi_{\mathrm{j}}$ are solutions of $y_{m} e^{u}$ and $x_{j}$ obtained from (1).

10 See Fuentsalz (1994) for details on the simultaneous strategy of aggressive branch expansion and price competition during that period.

${ }^{11}$ Descriptive statistics do not control for covariates and hence comparing mean values of variables before and after deregulation might give misleading results. 
Since $\pi\left(w e^{u}, p, z, t\right)$ is homogeneous of degree one in $w e^{u}$ and $p$, we express the above relationship in (2a) as

$$
\pi^{a} e^{u} / p_{1} \equiv \tilde{\pi}^{a} e^{u}=\pi\left(w e^{u}, p, z, t\right) / p_{1} \equiv \hat{\pi}(\hat{w}, \tilde{p}, z, t)
$$

where $\hat{w}_{j}=e^{u} w / p_{1}=\tilde{\mathrm{w}} \mathrm{e}^{\mathrm{u}}$ and $\tilde{p}_{m}=p_{m} / p_{1}$. Finally, $\tilde{\pi}^{a}=\pi^{a} / p_{1}$ is normalized actual variable profit and $\hat{\pi}(\hat{w}, \tilde{p}, z, t)$ is the normalized variable profit function. Note that the variable profit function and the normalized variable profit function are denoted by $\pi\left(\mathrm{we}^{\mathrm{u}}, \mathrm{p}, \mathrm{z}, \mathrm{t}\right)$ and $\hat{\pi}(\hat{w}, \tilde{p}, z, t)$, respectively. We rewrite (3) to express normalized actual profit as

$$
\ln \tilde{\pi}^{a}=\ln \hat{\pi}(\hat{w}, \tilde{p}, z, t)-u .
$$

For estimation purposes the formulation in (4) is complete when a parametric form of $\ln \hat{\pi}($.$) is assumed. We$ assume a translog from for $\ln \hat{\pi}(\hat{w}, \tilde{p}, z, t)$, i.e.,

$$
\begin{aligned}
\ln \hat{\pi}(\hat{w}, \tilde{p}, z, t)= & \alpha_{0}+\sum_{j} \alpha_{j} \ln \hat{w}_{j}+\sum_{q} \delta_{q} \ln z_{q}+\alpha_{t} t+\sum_{m} \beta_{m} \ln \tilde{p}_{m} \\
& +\frac{1}{2}\left\{\sum_{j} \sum_{k} \alpha_{j k} \ln \hat{w}_{j} \ln \hat{w}_{k}+\sum_{m} \sum_{l} \beta_{m l} \ln \tilde{p}_{m} \ln \tilde{p}_{l}+\sum_{q} \sum_{r} \delta_{q r} \ln z_{q} \ln z_{r}+\alpha_{t t} t^{2}\right\} \\
& +\sum_{j} \sum_{m} \gamma_{j m} \ln \hat{w}_{j} \ln \tilde{p}_{m}+\sum_{j} \sum_{q} \theta_{j q} \ln \hat{w}_{j} \ln z_{q}+\sum_{m} \sum_{q} \lambda_{m q} \ln \tilde{p}_{m} \ln z_{q}+\sum_{j} \alpha_{j t} \ln \hat{w}_{j} t \\
& +\sum_{m} \beta_{m t} \ln \tilde{p}_{m} t+\sum_{q} \delta_{q t} \ln z_{q} t \\
j, k & =1, \ldots, J ; \quad q, r=1, \ldots, Q ; \quad m, l=2, \ldots M
\end{aligned}
$$

with the following symmetry restrictions, $\alpha_{\mathrm{ik}}=\alpha_{\mathrm{ki}}, \beta_{\mathrm{ml}}=\beta_{\mathrm{lm}}, \delta_{\mathrm{qr}}=\delta_{\mathrm{rq}}$.

Rewrite (5) as

$$
\begin{aligned}
\ln \hat{\pi}(\hat{w}, \tilde{p}, z, t)= & \left.\ln \hat{\pi}(\hat{w}, \tilde{p}, z, t)\right|_{u=0}+u\left\{\sum_{j} \alpha_{j}+\sum_{j} \sum_{k} \alpha_{j k} \ln \tilde{w}_{j}\right. \\
& \left.+\frac{1}{2} \sum_{j} \sum_{k} \alpha_{j k} u+\sum_{j} \sum_{m} \gamma_{j m} \ln \tilde{p}_{m}+\sum_{j} \sum_{q} \theta_{j q} \ln z_{q}+\sum_{j} \alpha_{j t} t\right\}
\end{aligned}
$$

from which we can calculate profit technical inefficiency, $\ln \pi_{\mathrm{u}}($.$) , defined as potential profit loss due to$ technical inefficiency as 


$$
\begin{aligned}
\ln \pi_{u}(\tilde{p}, \tilde{w}, z, t, u) & =\left.\ln \hat{\pi}(\hat{w}, \tilde{p}, z, t)\right|_{u=0} \quad-\ln \tilde{\pi}^{a}=u\left\{1-\left[\sum_{j} \alpha_{j}+\sum_{j} \sum_{k} \alpha_{j k} \ln \tilde{w}_{j}\right.\right. \\
& \left.\left.+\frac{1}{2} \sum_{j} \sum_{k} \alpha_{j k} u+\sum_{j} \sum_{m} \gamma_{j m} \ln \tilde{p}_{m}+\sum_{j} \sum_{q} \theta_{j q} \ln z_{q}+\sum_{j} \alpha_{j t} t\right]\right\}
\end{aligned}
$$

It can seen from (7) that profit technical inefficiency, $\ln \pi_{u}$ depends on variable input and output prices, quasi-fixed factors, and time, unless the production technology is homogeneous. Equation (7) also provides an analytical solution relating output technical inefficiency $(u)$ and profit loss therefrom $\left(\ln \pi_{\mathrm{u}}().\right)$. Thus, one can go back and forth from production technical inefficiency to profit technical inefficiency. This result is not limited to homogeneous production technologies. Now we examine the rate of change in variable profit over time (labeled as the rate of productivity or overall productivity change), holding everything else constant (i.e., $\left.\partial \ln \tilde{\pi}^{a} / \partial t=\Delta \mathrm{OP}_{\mathrm{t}}\right)^{12}$. Since (from (7))

$$
\frac{\partial \ln \tilde{\pi}^{a}}{\partial t}=\frac{\left.\partial \ln \hat{\pi}(.)\right|_{u=0}}{\partial t}-\frac{\partial \ln \pi_{u}(.)}{\partial t} \Rightarrow \Delta O P_{t}=\Delta T C_{t}+\Delta T E_{t}
$$

the rate of productivity change $\left(\Delta \mathrm{OP}_{\mathrm{t}}\right)$ is decomposed into technical change $\left(\Delta T C_{t}\right)$ and profit technical efficiency change $\left(\Delta T E_{t}\right)$. Exogenous technical change (shift in the profit frontier $\left.\hat{\pi}()\right|_{.u=0}$ over time, ceteris paribus) is measured by $\Delta T C_{t}$ and change in technical efficiency (percent reduction in profit loss) is represented by $\Delta T E_{t}$.

Using the specification in (5) we get

$$
\Delta T C_{t}=\alpha_{t}+\alpha_{t t} t+\sum_{j} \alpha_{j t} \ln \tilde{w}_{j}+\sum_{m} \beta_{m t} \ln \tilde{p}_{m}+\sum_{q} \delta_{q t} \ln z_{q}
$$

which measures the rate of change in variable profit without technical inefficiency.

Similarly,

\footnotetext{
${ }^{12}$ Note that productivity change here is defined differently from total factor productivity change which can be affected by changes in prices ( $w$ and $p$ ) as well as the quasi-fixed factors/output attributes $(z)$.
} 


$$
\begin{aligned}
-\Delta T E_{t} & =u \sum_{j} \alpha_{j t}+\frac{\partial u}{\partial t}\left\{1-\left[\sum_{j} \alpha_{j} \sum_{j} \sum_{k} \alpha_{j k} \ln \tilde{w}_{j}\right.\right. \\
& \left.\left.+\sum_{j} \sum_{m} \gamma_{j m} \ln \tilde{p}_{m}+\sum_{j} \sum_{q} \theta_{j q} \ln z_{q}+\sum_{j} \alpha_{j t} t\right]\right\} \\
& +\sum_{j} \sum_{k} \alpha_{j k} u \frac{\partial u}{\partial t} .
\end{aligned}
$$

Note that $\Delta T E_{t}$ is not the same as change in output technical efficiency $\left(\partial e^{-u} / \partial t\right)$. It is possible for profit technical efficiency to decrease even $u$ increases because the former depends on prices and the $z$ variables.

\section{DATA}

The data used in this study is taken from the annual publication "Anuario de la Confederación de Cajas de Ahorros". Due to the increased mergers and acquisitions during the sample period (1986-1995) there has been a marked reduction in the number of Spanish savings banks. Over this period, twenty mergers and acquisitions took place: one in 1989, nine in 1990 (involving twelve banks), five in 1991 (involving eight banks), two in 1992 (involving three banks), two in 1993, and one in 1995. Consequently, the total number of savings banks declined from 75 in 1986 to 46 in 1995. We constructed an unbalanced panel data by retaining pre-merger savings banks as separate banks and treating the merged ones as new banks.

In the definitions of inputs and outputs, we use a value-added approach (Berger and Humphrey (1992). Following Humphrey and Pulley (1997), we take the view that banks provide two main categories of financial services: (1) intermediation and loans services (measured by three asset categories, viz., home loans, other loans, and interbank loans); and (2) payment, liquidity and safekeeping services (measured by a liability category, viz., core deposits). A change in accounting practice in 1992, however, forced us to aggregate all loan categories - home loans, other loans, and interbank loans -- into a single measure of loans enabling us to extend the present study through 1995.

Consequently, two output variables, viz., total loans and core deposits, are used. The three variable inputs used in this study are labor (number of employees), variable physical capital (furniture, fixtures and materials) and financial input (measured as cost of funds). The quantities of outputs and inputs are the averages of their balance sheet figures at the beginning and the end of the year. This averaging procedure is used to reduce errors due to fluctuations or growth over the year. Prices of outputs and variable inputs are obtained by dividing revenues of each output, and expenses of each input, by their respective quantities. 
In addition to the above output and input prices, some other quasi-fixed/control variables are also used in the variable profit function. We treat physical capital (immovable assets) and financial capital ${ }^{13}$ as quasi-fixed inputs. Assets composed of securities and investments (labeled as other assets) are used as control variables. This asset category accounts for significant differences in revenues among savings banks. The number of bank offices (Branch) is viewed as a quality/attribute of outputs because an increase in bank offices is likely to provide more convenience to the customers. Another output attribute/quality is the number of automatic teller machines (ATM).

Given that the savings banks have gone through mergers, one can control for this effect either by using a merger dummy variable, or using the time elapsed after the merger (age) as a control variable. The latter is preferred because the productivity effect of a merger, if any, is likely to change over time after the merger.

The dependent variable in our model is variable profit, calculated as revenues minus costs of variable inputs. We impose linear homogeneity restrictions on the variable profit function by using wages as numeriare. We also normalize all the variables by financial capital to control for heteroscedasticity (Berger and Mester 1999). Finally, the 1986 prices are used as the base year and we adjust all relevant variables (measured in value terms) using the consumer price index.

\section{ESTIMATION}

For estimation purpose the model outlined in (3) and (5) is extended to accommodate the revenue and cost share equations. Using duality results, we get

$$
\begin{aligned}
& \frac{\partial \ln \tilde{\pi}^{a}}{\partial \ln \tilde{p}_{m}}=\frac{\tilde{p}_{m} y_{m}}{\tilde{\pi}^{a}}=R_{m}, m=2, \ldots, M \\
& \frac{\partial \ln \tilde{\pi}^{a}}{\partial \ln \hat{w}_{j}}=-\frac{\tilde{w}_{j} x_{j}}{\tilde{\pi}^{a}}=-S_{j}, j=1, \ldots, J .
\end{aligned}
$$

From the variable profit function in (3) and (5), the above share equations can be expressed as

$$
\begin{aligned}
& R_{m}=\beta_{m}+\sum_{l} \beta_{m l} \ln \tilde{p}_{l}+\sum_{j} \gamma_{j m} \ln \tilde{w}_{j}+\sum_{q} \lambda_{m q} \ln z_{q}+\beta_{m t} t \\
& -S_{j}=\alpha_{j}+\sum_{k} \alpha_{j k} \ln \hat{w}_{k}+\sum_{m} \gamma_{j m} \ln \tilde{p}_{m}+\sum_{q} \theta_{j q} \ln z_{q}+\alpha_{j t} y,
\end{aligned}
$$

\footnotetext{
${ }^{13}$ Hughes et al. (1995), Berger and Mester (1999), among others, argue for the inclusion of financial capital in profit studies.
} 
which are used along with the normalized variable profit function in (3) and (5). Classical error terms are added to each of these equations. These error terms are assumed to be distributed with zero mean and constant variances and covariances over time. The system consisting of $M+J$ equations is then estimated using nonlinear iterative seemingly unrelated regression (ITSUR) techniques.

Several models with and without technical inefficiency are estimated. To conserve space, however, we report results from the following models. Model 1 is the standard neo-classical variable profit function model that ignores technical inefficiency completely. Model 2 considers technical inefficiency to be time-invariant. Models 3 and 4 accommodate time-varying technical inefficiency. In Model 3 we specify $u_{i t}$ as

$$
u_{i t}=\mu_{i}\left(1+b_{t} t\right)
$$

where $\mu_{\mathrm{i}}$ is the bank-specific parameter, estimated from the coefficient of the dummy variable $\mathrm{D}_{\mathrm{i}}$, which equals one for bank $i$ and zero for all other banks. The other parameter $b_{t}$ is common to all banks. Thus, the temporal pattern of technical inefficiency is assumed to be the same for all banks. Letting $b_{t}$ vary across banks would substantially increase the number of parameters. ${ }^{14}$ Model 4 differs from Model 3 in the specification of technical inefficiency. The form of inefficiency used in Model 4 is

$$
u_{i t}=\mu_{i}\left(1+b_{t} t+b_{a} A T M B R\right)
$$

where ATMBR denotes number of ATMs per branch. The idea here is to make technical inefficiency formulation more flexible and to test whether inclusion of output quality variable ATMBR affects technical inefficiency. Thus, Model 4 is the most general model, and Models 1-3 are nested in it.

In Model 2, technical inefficiency is estimated relative to the best bank in the sample (Schmidt and Sickles, 1984), i.e.,

$$
\hat{u}_{i}=\hat{\mu}_{i}-\max _{i}\left\{\hat{\mu}_{i}\right\}
$$

where $\hat{\mu}_{i}$ is the estimated coefficient of the bank dummy $\mathrm{D}_{\mathrm{i}}$. When $u$ is allowed to be time-varying (Models 34), we estimate technical inefficiency relative to the best bank in each year, i.e.,

$$
\hat{u}_{i t}=\hat{\mu}_{i t}-\max _{i}\left\{\hat{\mu}_{i t}\right\}, \quad t=1, \ldots, T
$$

\footnotetext{
${ }^{14}$ It is possible, in principle, to specify a much more flexible from of tehcnical inefficiency such as $u_{i t}=b_{0 t}+b_{1 t} t+b_{2 t} t^{2}$ (Cornwell et al. (1990)). Such a formulation, however, requires estimation of $3 N$ parameters in $u_{i t}$ alone. Thus, unless $T$ is very large, it is better to use some parsimonious specifications. We also tried some other forms of $u_{i t}$ such as $u_{i t}=\mu_{i}\left(1+b_{t} t+c\right.$ age $)$ and $u_{i t}=\mu_{i}\left(1+b_{t} t+c\right.$ merge $)$. Results from these models are quite similar to those obtained from the specification in (13). These esults can be obtained from the authors upon request.
} 
where $\hat{\mu}_{i t}$ is the estimated value of $u_{i t}$ obtained from (13) or (14). Once technical inefficiency is estimated, potential output loss (percent) can be calculated from $\left(e^{\hat{u}}-1\right)$. Similarly, potential profit loss (percent) due to technical inefficiency for each bank can be calculated either from (7), or from

$$
\frac{\left.\hat{\pi}(\cdot)\right|_{u=0}-\tilde{\pi}^{a}(\cdot)}{\tilde{\pi}^{a}(\cdot)}=\frac{\left.\hat{\pi}(\cdot)\right|_{u=0}}{\tilde{\pi}^{a}(\cdot)}-1,
$$

the estimate of which can be obtained from (7) by taking the exponential of the right hand side of (7) and then subtracting unity from it. The above formula is used to calculate profit loss due to technical inefficiency for each bank in every year. Although technical inefficiency is time-invariant, profit loss due to technical inefficiency can change over time. This is because $u$ interacts with $w, y, z$, and $t$ variables.

\section{RESPONSES TO DEREGULATION}

We now concentrate on the overall significance of the deregulatory initiatives on the performance of saving institutions and its market condition in general. Since the deregulatory changes are scattered primarily over the 1986-1990 period, as noted earlier we consider 1986-1990 as the deregulatory period and 1991-1995 as the post-deregulatory period. After specification testing among the four models discussed in the preceding section, we report results in terms of output and profit efficiency, first, and then examine technical change, change in efficiency, and overall productivity growth.

To examine the presence of output technical inefficiency we test the specification of Model 1 against Models 2-4, which include technical inefficiency in some forms. We reject Model 1 against Models 2-4 separately at the 5\% level of significance. Then we test whether technical inefficiency is time-invariant or not. The time-invariant output technical inefficiency specification (Model 2) is nested in Models 3 and 4. The standard t-test on the $b_{t}$ coefficient in Models 3 rejects Model 2 in favor of Model 3 at the $1 \%$ level of significance. A positive value of $b_{t}$ indicates an increase in technical inefficiency over time, ceteris paribus. Finally, Model 3 is nested in Model 4. The t-test on the coefficient of ATMBR in Model 4 is found to be statistically significant at the $10 \%$ level of significance. Based on this $10 \%$ significance level, we consider Model 4 to be the preferred model. ${ }^{15}$ Here we observe a positive relationship between technical inefficiency and ATMs per branch. Although the statistical significance of such relationship is marginal nevertheless it gives us an important piece of information, viz., an increase in ATMs per branch tends to increase technical inefficiency. Since increase in ATMs per branch reflects enhancement of output quality (not captured in the

\footnotetext{
${ }^{15}$ However, if one considers the $10 \%$ significance level too high, then the best model is Model 3. Here we discuss results from both the models.
} 
measured outputs) part of the deterioration of technical efficiency might be due to such output quality enhancements.

\section{Output Technical Inefficiency $(u)$ and Profit Loss $\left(\ln \pi_{\mathrm{u}}\right)$}

Output technical inefficiency $(u)$ and profit losses therefrom $\left(\ln \pi_{\mathrm{u}}\right)$ are reported for Models 2, 3 and 4 in Table 2. The first three columns of Table 2 report the mean values (by year) of output technical inefficiency (potential output losses) corresponding to Models 2-4 followed by the mean values of potential profit losses. In Model 4, we find that (potential) output loss increased from 16.19\% in 1986 to $27.64 \%$ in 1995, the mean being $20.76 \%$. The corresponding figures in Model 3 are $15.4 \%$ to $27.49 \%$ with a mean of $20.75 \% .{ }^{16}$ Mean output losses due to technical inefficiency increased from $18.40 \%$ (in Model 4) during the years of deregulation to $23.11 \%$ in the post-deregulatory years. The corresponding figures for Model 3 are $18.22 \%$ and $23.29 \%$, respectively.

Entries in the last 3 columns of Table 2 portray the evidence of an increase in profit technical inefficiency (i.e., loss in potential profit because of the inability to produce the maximum possible output vector, ceteris paribus) from the beginning to the end of the sample period. However, the percentage of profit losses in Model 3 and 4 declined from 25.17\% (21.16\%) in 1986 to 22.8\% (20.06\%) in 1990 and then increased to $34.27 \%$ (32.42\%) in 1995. ${ }^{17}$ Models 3 and 4 both predicted an increase in mean profit losses, on average, from the deregulatory years to the post-deregulatory years (see the last two rows of Table 2). This result is not surprising since the mean output losses increased during the post-deregulation years.

In order to check for robustness of these results, we re-estimated all the models using the alternative profit function (Humphrey and Pulley (1997)) instead of the standard profit function used in the present paper. The alternative profit function is identical to the standard profit function in (5) except that the output vector, $y$, replaces the output price vector, $p$. Berger and Mester (1999) suggest that the alternative profit may be helpful when (i) there are substantial unmeasured differences in the quality of banking services; (ii) outputs are not completely variable; (iii) output markets are not perfectly competitive; and (iv) output prices are not accurately measured. The results from the alternative profit function are reported in the appendix (Table A.1). Potential output loss predicted by each model under the alternative profit function is somewhat higher in magnitude compared to the corresponding model under standard profit function. The same conclusion is reached when potential profit losses are compared. These differences are, however, not

16 Within each model we find substantial variation in both technical inefficiency and profit losses among banks. However, a high degree of correlation exists in the efficiency ranking of banks obtained from different models. The correlation coefficients of (potential) output loss due to technical inefficiency across different models are: 0.90 (Models 2 and 3), 0.89 (Models 2and 4), and 0.99 (Models 3 and 4). That is, technical inefficiency of banks across models is quite robust.

17 Note that (percent) profit loss depends on technical inefficiency as well as other variables that appear in the profit function. Thus, it is possible for profit losses to decline even if technical inefficiency increases. 
significant. A pre- and post -deregulation comparison shows that output and profit losses increased during the post-deregulatory years. This prediction is true for both Models 3 and 4. Again these results are similar to those obtained from the standard profit function.

We find estimates of potential output and profit losses under both standard and alternative profit models to be highly correlated. Rank correlation coefficients of potential output and profit losses between these two models are 0.84 and 0.92 , respectively. We also find a negative and statistically significant correlation between efficiency and standard average cost ratio, and a positive and significant correlation between efficiency and profitability ratio. These findings are consistent with Berger and Mester (1999), Humphrey and Pulley (1997), and suggest that our efficiency measures are quite robust and are not simply the consequences of our specifications or methods.

\section{Technical Change, Change in Profit Technical Efficiency, and Productivity Growth}

Now we focus on the productivity change results which is the sum of technical change ${ }^{18}$ (shifts in the profit frontier through time, ceteris paribus) and change in profit technical efficiency components (see equation (8)). These results for the standard profit function are presented in Tables 3 and 4. The corresponding tables for the alternative profit functions are Tables A.2 and A.3. Tables 3 and A.2 report mean values of technical change per year across all banks for Models 1-4. All the models show technical progress (i.e., outward shift in the profit frontier) increases savings banks profits over time although the progress slows down for some years. These estimates from the alternative profit function are somewhat smaller, but the difference is not significant. In all models under the alternative profit function, we also observe a declining trend in technical change. Estimates of technical progress obtained from Models 3 and 4 are $5.14 \%$ and $5.08 \%$ in $1986 ; 4.43 \%$ and $4.27 \%$ in 1995 with a mean of $4.45 \%$ and $4.39 \%$ per year. These estimates are somewhat higher but consistent with Grifell and Lovell (1997) who found technical progress at the rate of $1.9 \%$ over the $1986-1993$ period. ${ }^{19}$ The rate of technical progress, on average, during the postderegulation years is found to be somewhat smaller compared to its counterpart during the period of deregulation. This is true for all the models in both standard and alternative profit functions (see the last two rows of Table 3 and Table A.2).

In Tables 4, first, we report change in profit technical efficiency results and then the overall productivity change. The same sequence is followed for the alternative profit functions in Table A.3. The first three columns report changes in profit technical efficiency in Model 2-4 and the last four columns report rates of overall productivity change. In Models 3 and 4 we find that the contribution of profit

\footnotetext{
${ }^{18}$ Note that this definition of technical change is based on the profit function not the production possibility function.

${ }^{19}$ The relatively higher mean technical progress in this study compared with Grifell and Lovell (1997) is not surprising for several reasons. This paper uses a profit maximization framework, incorporates a large sample size, and use different methodology and estimation technique, and different measures of inputs and outputs.
} 
technical efficiency to productivity growth is negative. The mean values of profit technical efficiency change in Models 3 and 4 are $-2.79 \%$ and $-2.56 \%$, respectively. The corresponding figures obtained from the alternative profit functions are $-1.98 \%$ and $-1.77 \%$. We also find an improvement in profit efficiency change after deregulation predicted by both the standard and alternative profit functions. In the standard profit models the mean of profit efficiency change increased from $-3.32 \%$ to $-2.27 \%$ in Model 3 and $3.01 \%$ to $-2.12 \%$ in Model 4, whereas in the alternative profit models these numbers for Models 3 and 4 are $-2.15 \%$ to $-1.81 \%$, and $-2.00 \%$ to $-1.54 \%$. Profit technical efficiency has improved over time in spite of deterioration of output technical efficiency (see Table 2) because output technical efficiency as well as prices and the $\mathrm{z}$ variable affect profit technical efficiency.

Because of the negative contributions of profit technical efficiency change, the overall productivity changes in Models 3 and 4 are smaller than technical changes. In Model 3, the overall productivity change increased from $1.44 \%$ (per year) during deregulatory years to $1.87 \%$ per year during the post-deregulatory years. The mean for the entire sample period is $1.66 \%$ per year. The comparable statistics in Model 4 are $1.74 \%$ and $1.92 \%$ and the overall mean is $1.83 \%$. These figures are somewhat higher in the alternative profit function as can be seen from the last 2 rows of Table A.3. ${ }^{20}$

Our evidence above indicates that during the sample years the savings banks experienced high levels of technical inefficiency along with a significantly high rate of technical progress. These banks also reported an increase in productivity growth. Taking all accounts into consideration, it seems that despite the adjusting efforts by the banks, the continuous deregulatory initiatives during the sample period prevented banks from producing the maximum possible output vector while concerned with intense competition for market share. Some of these banks adjusted quickly to the new environment while others struggled to keep pace to the best-practiced ones causing increased technical inefficiency. Under these circumstances, the evidence of average output losses is not unusual. On the other hand, it seems that increased convenience provided by branch expansion has been an effective competitive strategy since savings banks showed technical progress every year. The technical progress was however a bit slower during the 1991-1993 period when savings banks launched its branch expansion strategy while intensifying price competition. These costly schemes prevented banks from immediate profits but positioned them well for an increasingly higher market share in the banking business. Despite this apparent trade off, savings banks reported positive productivity growth. $^{21}$

\footnotetext{
${ }^{20}$ Larger banks reported relatively higher productivity growth than their smaller counterparts. This result holds for both standard and alternative profit functions, and is consistent with Wheelock and Wilson (1999). Similarly, banks with higher technical progress (ranked from highest to lowest technical progress) show increasing profit efficiency and productivity growth.

${ }^{21}$ We also find inverse relationship between productivity growth and growth of loan to deposit ratio. This could be due to the fact that banks with rapid expansion in loan activities follow a less stringent lending criteria and thus exposed to
} 


\section{SUMMARY AND CONCLUSIONS}

In this study we use a flexible variable profit function to investigate the effect of deregulation on the performance of Spanish savings banks during 1986-1995, the period during which the Spanish banking industry went through major regulatory reforms. The paper uses a comprehensive statistical approach and considers a profit function model that measures both technical inefficiency and profit loss. We also decompose productivity change (the rate of change in variable profit) into technical change and change in technical efficiency components. We do so without making any distributional assumptions on technical inefficiency and other statistical noise terms in the variable profit function and variable profit share equations. Several alternative models with different specifications of technical inefficiency are also used and results from these models are compared.

The time varying output technical inefficiency models predict deterioration in technical efficiency over the time. Depending on the specification of output technical inefficiency, the overall mean of potential output loss (output technical inefficiency) and profit loss therefrom (profit technical inefficiency) varied from $19.79 \%$ to $20.76 \%$ and $25.28 \%$ to $30.91 \%$, respectively. All the models predict a high rate of technical progress. The overall mean technical progress (per year) ranged from $4.1 \%$ to $5.86 \% .{ }^{22}$ Despite an increased output technical inefficiency, we find evidence of positive productivity growth defined as the sum of profit technical efficiency change and technical change.

The performance of the Spanish savings banks in the post-deregulatory environment is found to be slightly better. The post deregulatory period showed a higher productivity growth rate (an average of $1.90 \%$ during 1991-1995 compared to $1.15 \%$ during the 1986-1990 period). Finally, the new environment brought by the deregulation and liberalization has prompted banking institutions into a more competitive industry. The Spanish savings banks' experience reveals that the aggressive interest rate competition and the expansion strategy of branching network apparently have caused an initial decrease in profit efficiency. However, these developments also positioned the industry to play a more dominant role in the depository industry where savings banks show a positive productivity growth in their production process.

higher credit risk resulting higher loan losses. Such explanation is consistent with experiences in U.S. (Clair (1992)) and Finland (Solttila and Vihriala (1994)).

${ }^{22}$ Estimates from the alternative profit function model also reveal similar results. The mean (potential) output and profit losses were $23.94 \%$ to $26.20 \%$, and $27.09 \%$ to $32.29 \%$, respectively. Similarly, mean technical progress ranged from $3.8 \%$ to $5.82 \%$. 


\section{References}

Bauer, A.N. Berger, and D. B. Humphrey. "Efficiency and Productivity Growth in U.S. Banking," in The Measurement of Productive Efficiency: Techniques and Applications, ed. H.O. Fried, C.A.K. Lovell, and S.S. Schmidt (Oxford: Oxford University Press), (1993), 386-413.

Berg, S.A., F. Førsund, and E. Jansen, "Malmquist Indices of Productivity Growth During the Deregulation of Norwegian Banking 1980-89." Scandinavian Journal of Economics 94, (1992), (Supplement), S211S228.

Berger, A.N., R.S. Demsetz, and P.E. Strahan. "The Consolidation of the Financial Services Industry: Causes, Consequences, and Implications for the Future." Journal of Banking and Finance 23, (1999), forthcoming.

Berger, A.N, D. Hancock, and D.B. Humphrey, "Bank Efficiency Derived from Profit Function." Journal of Banking and Finance 17, (1993), 317-47.

Berger, A.N., and D.B. Humphrey, "Measurement and Efficiency Issues in Commercial Banking." in Z. Griliches, ed., Output Measurement in the Service Sectors, National Bureau of Economic Research Studies in Income and Wealth, Volume 56. (1993). Chicago and London: The University of Chicago Press.

Berger, A.N., and D.B. Humphrey, Efficiency of Financial Institutions: International Survey and Directions for Future Research, European Journal of Operational Research 98, (1997),175-212.

Berger, A.N., L. J. Mester, What Explains the Dramatic Changes in Cost and Profit Performance of the U.S. Banking Industry? Working Paper No. 99-1, (1999), Federal Reserve Bank of Philadelphia.

Berger, A.N., L. J. Mester, "Inside the Black Box: What Explain Differences in the Efficiency of Financial Institutions?" Journal of Banking and Finance, 21, (1997), 895-947.

Bhattacharyya, A., C.A.K. Lovell \& P. Sahay. "The Impact of Liberalization on the Productive Efficiency of Indian Commercial Banks.” European Journal of Operational Research 98, (1997), 332-345.

Canals, J., "Universal Banking, International Comparisons and Theoretical Perspectives.” Oxford, (1997), Clarendon Press-Oxford.

Clair, R.T., "Loan Growth and Loan Quality: Some Preliminary Evidence from Texas Banks." Economic Modelling 11, (1992), 134-44.

Cornwell, C., P. Schmidt, and R. C. Sickles, "Production Frontiers with Cross-Sectional and Time-Series Variation in Efficiency Levels." Journal of Econometrics 46, (1990), 185-200.

Elyasyiani, E. and S.M. Mehdian, "The Comparative Efficiency Performance of Small and Large US Commercial Banks in the Pre- and Post-deregulation Eras.” Applied Economics 27, (1995), 1069-079.

Fuentsalz, L., "Liberalización y Eficiencia de la Banca al por Menor en España." Perspectivas del Sistema Financiero, 48, (1994), 61-77.

Fukuyama, H., Measuring Efficiency and Productivity Growth in Japanese Banking. A Nonparametric Frontier Approach.” Applied Financial Economics 5, (1995), 95-117. 
Gilbert, R. A., and P.W. Wilson, "Effects of Deregulation on the Productivity of Korean Banks." Journal of Economics and Business, 50(2), (1998), 133-56.

Grifell, E. and C.A.K. Lovell, "Deregulation and Productivity Decline: The Case of Spanish Savings Banks.” European Economic Review 40, (1996), 1281-1303.

Grifell, E., and C.A.K. Lovell, “The Sources of Productivity Change in Spanish Banking.” European Journal of Operational Research 98(2), (1997), 364-80.

Hasan, I., Hunter, W.C. and Lozano-Vivas, A. "Deregulation, Strategy, Bank Performance, and Efficiency: The Spanish Experience." Research in International Business and Finance, Special Issue on European Monetary Union Banking Issues: Historical and Contemporary Perspectives, edited by Irene FinelHonigman: JAI Press, 1999.

Hughes, J., W. Lang, L. Mester, and C.G. Moon, "Recovering Technologies that Account for Generalized Managerial Preferences: An Application to Non Risk-Neutral Banks." Working Paper No 95-8/R, (1995), Federal Reserve Bank of Philadelphia.

Hughes, J., Lang, W., Mester, L. and Moon, C.G. "Efficiency Banking Under Interstate Branching." Journal of Money, Credit, and Banking 28, (1996), 1045-071.

Humphrey, D.B., "Cost and Technological Change: Effects from Bank Deregulation." Journal of Productivity Analysis 4, (1993), 9-34.

Humphrey, D.B. and L.B. Pulley.,"Bank's Responses to Deregulation: Profits, Technology, and Efficiency." Journal of Money, Credit and Banking 29(1), (1997), 73-93.

Kumbhakar, S.C., "Production Frontiers, Panel Data, and Time-Varying Technical Inefficiency." Journal of Econometrics, 46, 1990, 201-212.

Kumbhakar, S.C., "Efficiency Measurement with Multiple Outputs and Multiple Inputs." Journal of Productivity Analysis 7, (1996), 225-55.

Lozano-Vivas, A., "Profit Efficiency for Spanish Savings Banks." European Journal of Operational Research. 98(2), (1997), 381-394.

Lozano-Vivas, A., "Efficiency and Technical Change for Spanish Banks." Applied Financial Economics 8, (1998), 289-300.

Schmidt, P. and R. C. Sickles, "Production Frontiers and Panel Data." Journal of Business \& Economic Statistics 4, (1984), 367-74.

Smith, R.T. (1997), "Banking Competition and Macroeconomic Performance." Working paper, University of Alberta, (1997), Edmonton Canada.

Solttila, H. and V. Vihriala, "Finnish Bank's Problem Assets: Result of Unfortunate Asset Structure or Too Rapid Growth?” Bank of Finland Discussion Papers 23/94 (1994).

Vives, X., "Deregulation and Competition in Spanish Banking." European Economic Review 34, (1990), 403-11. 
Vives, X. "Regulatory Reform in European Banking.” European Economic Review 35, (1991a), 505-15.

Vives, X. "Banking Competition and European Integration." In: A. Giovanni and C. Mayer, eds., European Financial Integration, Cambridge University Press, Cambridge, (1991b).

Wheelock, D. C. and P.W. Wilson, "Technical Progress, Inefficiency, and Productivity Change in U.S. Banking, 1984-1993.” Journal of Money, Credit, and Banking 31(2), (1999), 212-234.

Zaim, O. "The Effect of Financial Liberalization the Efficiency of Turkish Commercial Banks." Applied Financial Economics 5, (1995), 257-64.

Table 1: Descriptive Statistics of Spanish Saving Banks

\begin{tabular}{|l|c|c|c|c|c|}
\hline Variables & \multicolumn{5}{|c|}{ Years } \\
\hline & 1986 & 1991 & 1995 & $1986-1990$ & $1991-1995$ \\
\hline Financial margin & $4.9 \%$ & $3.5 \%$ & $3.8 \%$ & $5.0 \%$ & $4.3 \%$ \\
\hline Interest cost & $5.4 \%$ & $6.9 \%$ & $7.2 \%$ & $6.2 \%$ & $6.9 \%$ \\
\hline $\begin{array}{l}\text { Fee income } \\
\text { to assets }\end{array}$ & $0.28 \%$ & $0.45 \%$ & $0.56 \%$ & $0.36 \%$ & $0.51 \%$ \\
\hline $\begin{array}{l}\text { Number of branches } \\
\text { Number of saving } \\
\text { Banks }\end{array}$ & 12,831 & 14,031 & 15,029 & 13,485 & 14,619 \\
\hline $\begin{array}{l}\text { Average ATM per } \\
\text { bank }\end{array}$ & 40 & 185 & 301 & 74 & 48 \\
\hline $\begin{array}{l}\text { Market share of } \\
\text { deposits }\end{array}$ & $40.1 \%$ & $44.1 \%$ & $45.3 \%$ & $41.3 \%$ & $44.6 \%$ \\
\hline $\begin{array}{l}\text { Market share } \\
\text { of loans }\end{array}$ & $30.4 \%$ & $35.9 \%$ & $39.5 \%$ & $33.0 \%$ & $37.9 \%$ \\
\hline \begin{tabular}{l} 
Loan to deposits \\
\hline
\end{tabular} & $46.3 \%$ & $60.4 \%$ & $63.6 \%$ & $52.1 \%$ & $62.4 \%$ \\
\hline
\end{tabular}


